\title{
Near-Field Route Optimization-Supported Polar Ice Navigation via Maritime Radar Videos
}

\author{
Xinwei Lin $\mathbb{( D},{ }^{1,2}$ Shengzheng Wang $\mathbb{D}^{2},{ }^{2}$ Xuesheng Zhang $\mathbb{D}{ }^{2}$ Tsung-Hsuan Hsieh $\mathbb{D},^{2}$ \\ Zhen Sun ${ }^{(D)}{ }^{2}$ and Tingliu $X u \mathbb{1 D}^{2,3}$ \\ ${ }^{1}$ College of Information Engineering, Shanghai Maritime University, Shanghai 201306, China \\ ${ }^{2}$ Merchant Marine College, Shanghai Maritime University, Shanghai 201306, China \\ ${ }^{3}$ Faculty of Maritime and Transportation, Ningbo University, Ningbo 315832, China
}

Correspondence should be addressed to Shengzheng Wang; szwang@shmtu.edu.cn

Received 17 August 2021; Accepted 28 October 2021; Published 18 November 2021

Academic Editor: Eneko Osaba

Copyright (c) 2021 Xinwei Lin et al. This is an open access article distributed under the Creative Commons Attribution License, which permits unrestricted use, distribution, and reproduction in any medium, provided the original work is properly cited.

The accurate design of ship routing plans in arctic areas is not easy, considering that navigation conditions (e.g., weather, visibility, and ice thickness) may change frequently. A ship's crew identifies sea ice in arctic channels with the help of radar echoes, and ship maneuvering decisions are made to avoid navigation interference. Ship officials must manually and consistently change the ship's route of travel, which is time-consuming and tedious. To address this issue, we propose a near-field route optimization model for the purpose of automatically selecting an optimal route with the help of radar echo images. The ship near-field route optimization model uses a multiobjective optimal strategy considering factors of minimum navigation risk and steaming distance. We verified the model's performance with the support of the Xuelong voyage dataset. This research finding can help a ship's crew to design more reasonable navigation routes in polar channels.

\section{Introduction}

The thawing of ice in polar regions is accelerating as the earth becomes warmer. This enables the further performance of economic activities and exploitation of polar resources (e.g., transferring goods between Asia and North America) [1], and polar shipping and science investigation have attracted significant attention [2-5]. Studies have suggested that it is not easy to design accurate sailing plans in polar areas due to unpredictable weather and ice conditions. Moreover, the rough ice in Polar Regions significantly decreases navigation safety, and ship officials' sudden distraction may lead to serious maritime accidents. Note that icebreaker facilities installed on ships may fail to completely break ice in arctic waters, and maritime accidents are more probable in ice-covered areas than in open seas [6-10].

Many efficient frameworks have been proposed to enhance maritime traffic safety in polar regions, such as the global Polar Code [11]. Scholars employ multiple data sources (e.g., satellite images and ice model data) to obtain ship navigation environment information, which is used to fine-tune ship voyage plans $[12,13]$. Indeed, maritime traffic safety in polar regions can be significantly improved with the use of increasing amounts of weather and ice condition information $[14,15]$. Several commercial route optimization tools have been developed to determine ship routes in polar areas. Kotovirta et al. presented a greedy optimization algorithm using Powell's method and developed a prototype tool based on ice and ship transit modeling for route optimization through ice fields [16]. Much attention has been paid to the optimization of routes, considering such factors as ice conditions, icebreaker assistance, fuel consumption, and total cost [17-21]. Choi et al. proposed an uncertaintybased path planning model to find an optimal route under time-varying stochastic constraints [22], modeling ship path planning in ice-covered waters as a dynamic stochastic path planning problem.

Hui et al. presented a satellite-based sea-ice navigation system (SatSINS) that employed remote sensing and meteorological data to determine optimal maritime 
navigational routes in ice-covered waters [23]. Liu et al. utilized vector-formatted ice data and navigation codes in the northern regions to divide ice-covered waters into navigable and unnavigable areas. A road network-like graph was built to simulate areas with ice obstacles with Voronoi diagrams to obtain safe and short routes for different types of ships between origin-destination (OD) pairs [24]. Studies have focused on ship speed prediction with numerical and semiempirical models considering features of ice fields and ship maneuverability. Montewka et al. introduced probabilistic, data-driven models to predict ship speeds and situations where a ship is likely to become stuck in ice, based on the effects of ice features such as thickness and concentration of level ice, ice ridges, and rafted ice [25]. Kuuliala et al. analyzed ship maneuvering performance in ice conditions by fine-tuning the ship resistance magnitude caused by seaice ridge keels [26]. Lehtola et al. presented a route optimization framework to find safe and efficient shipping routes in ice-covered waters by combining multisource input data with an A-star-based algorithm [27]. Topaj et al. considered icebreaker assistance as an integral part of the overall route optimization problem and employed economic criteria to optimize both ship routing and icebreaker involvement [28]. Other relevant studies have been published $[14,29-36]$.

Two limitations significantly impede ice navigation safety: (1) the map spatiotemporal resolution for sea-ice concentration is too low and cannot meet ship navigation requirements; (2) sea-ice concentration maps are considered as a stationary environment, which is not always the case in the real world. Specifically, sea ice can melt or move with unpredicted trajectories due to weather and ocean currents. Hence, well-trained navigators are needed for navigation in near-field ice-covered areas to enhance maritime traffic safety. Indeed, polar ice navigation is a path optimization problem with multiple-target constraints (i.e., ice, wind, wave, and current). We can observe real-time ice navigation situations with the support of various data sources (such as satellite images, ice model data, weather observations and forecasts, and radar data). Shipborne navigators fine-tune (and optimize) travel routes by identifying both navigable and unnavigable areas with the support of radar echoes, which they must carefully check to recognize ice magnitudes, ridges, and categories (rafted or floating ice), considering that ice feature details in maritime images are too trivial to be identified.

We present a ship routing optimization model considering multiobjective constraints (e.g., navigation risk and minimum travel time) via ice condition recognition. Previous studies have suggested that evolutionary algorithms perform satisfactorily on multiobjective optimization problems [37, 38]. Multiobjective evolutionary algorithms (MOEAs) probabilistically process a population of solutions, which enables a global search with little knowledge about the objectives, and the efficient approach of a Pareto set with a single simulation run [39-42]. Thus, we employ an MOEA to solve the proposed near-field route optimization problem. In addition, we present a macro- and microscale route optimization system that provides optimal global routes for ships sailing in ice areas in terms of maps of sea-ice concentration. Our contributions can be summarized as follows:

(i) We address the problem of designing ship routing plan automatic in arctic areas with sea-ice data and radar video

(ii) We propose an ice-condition model using radar echoes to recognize ship near-field ice conditions

(iii) We develop a near-field route optimization method and employ MOEAs to find optimal ship near-field routes to ensure the safety and reliability of the voyage

The rest of this paper is organized as follows. The ship near-field ice condition model based on real-time radar echo images is presented in Section 2. The near-field route optimization problem is detailed in Section 3, and ship route optimization in polar ice-covered waters is discussed in Section 4. Section 5 relates our conclusions.

\section{Radar Echo-Supported Ice Recognition Model}

Numerous irregular echoes can be found in a typical radar echo image of a polar ice area, which are indeed sea ice (see Figure 1). The ship navigator must recognize sea ice from the radar echo range, shape, and size and devise a reasonable routing strategy. To address this issue, we establish an ice recognition model based on the radar imaging features of sea ice. Radars currently equipped on ships start in a pulse scanning mode that involves $9 \mathrm{GHz} \mathrm{X}$-band radar and $3 \mathrm{GHz}$ $\mathrm{S}$-band radar. Assuming that the antenna radiation intensity evenly distributes at power points, the received echo power (echo intensity) for a ship target is formulated as

$$
P_{r}=\frac{P_{t} G^{2} \lambda^{2} \sigma}{(4 \pi)^{3} R^{4}},
$$

where $P_{t}$ is the antenna transmission power, $G$ is the antenna gain, $R$ is the distance between the antenna and target, $\sigma$ is the effective scattering cross section of the target, and $\lambda$ is the wavelength. We note that the radar surveillance range is affected by inherent radar parameters (e.g., wavelength, transmit power, and antenna gain), target distance, and effective scattering cross section. For a given radar range (i.e., $\lambda$, $P_{t}$, and $G$ are constant), the radar echo intensity is positively proportional to the effective scattering cross-sectional area of the maritime target and negatively proportional to the fourth power of the target distance. Radar equipment performance is mainly constrained to the effective scattering cross-sectional area $\sigma$ and target distance $r$ of the radar target when the radar is in good condition. Note that maritime target echo in radar images is proportional to the effective reflection area of the radar and the target size. Figure 2(a) demonstrates the relationship between target size variation in the real world and echoes in radar images, and Figure 2(b) presents the target echo imaging variation tendency at different distances.

Therefore, sea ice in the polar ice area shows quite similar reflection features. Specifically, the size and distance of the radar echo demonstrate effective scattering of the crosssectional area of the target, and the target size is obtained as 


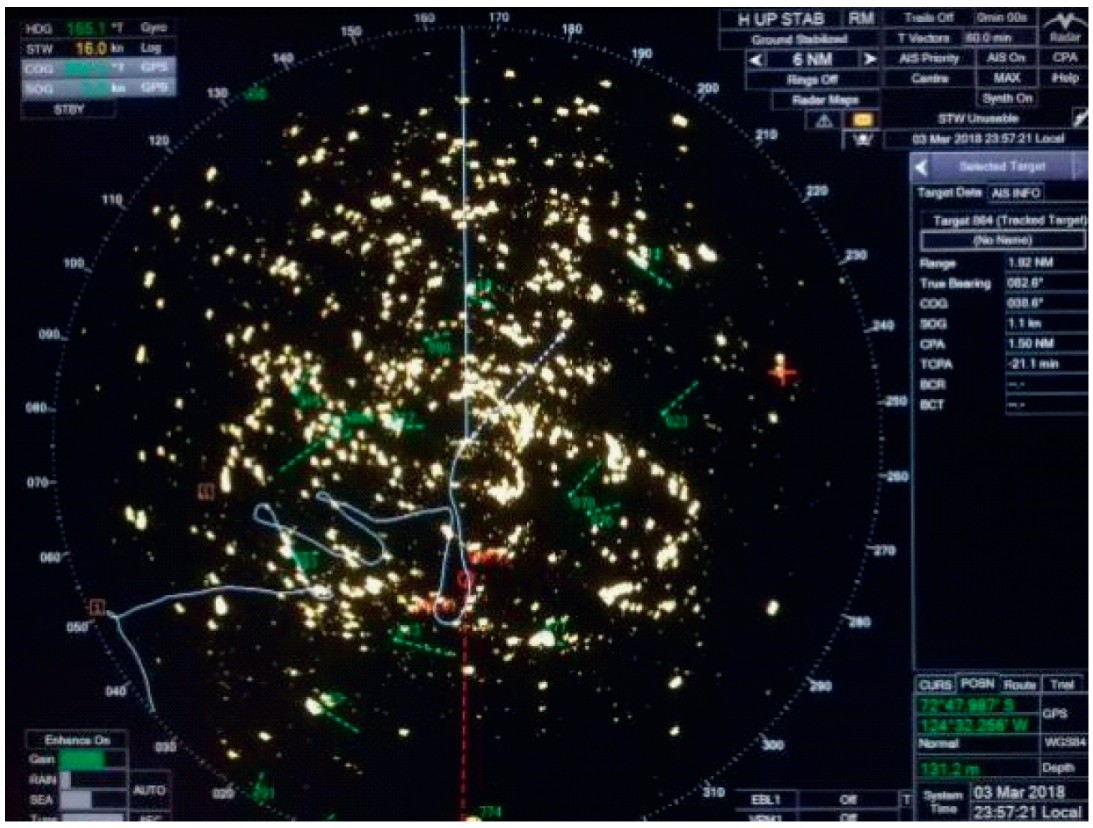

FIgure 1: Typical radar echo image in polar ice-covered area.

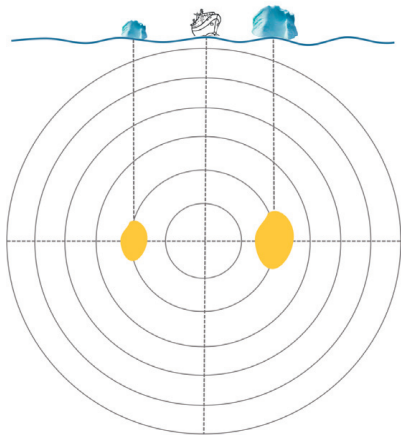

(a)

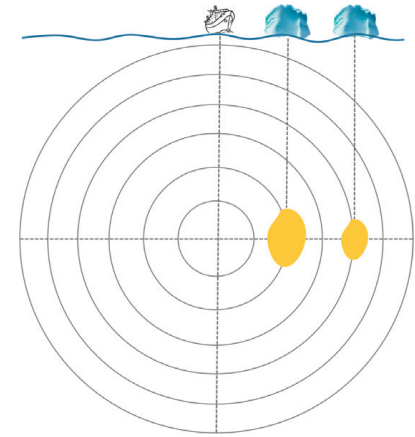

(b)

FIgURE 2: Ice echoes in radar images in various conditions.

$$
S_{t}=\Phi(r, \delta)
$$

where $S_{t}$ is the target size, $r$ is the target echo distance, $\delta$ is the target echo size for a given range, and $\Phi$ is the radar echo imaging mapping function obtained by radar testing and observation. It is essential to preprocess radar videos before determining the target echo size. For instance, we need to identify the geographic location of the radar scanning center based on the GPS position $\left(\varphi_{0}, \lambda_{0}\right)$ and set up an origin for the Cartesian plane coordinate system. Maritime regulation standards suggest that the diameter of the radar operational area is $320 \mathrm{~mm}$, and the display range of the radar is $R$. The radar display has a resolution of $96 \mathrm{DPI}$, and thus the equivalent distance of pixels $\tau=3.066 * R / n m$ meters per pixel. The radar video can be decomposed into monochrome images, and thus we employ a median filter to segment the background and target (see Figure 3 ). We can obtain the processed radar target echoes by marking out both echo center positions and sizes (see equation (3)).

$$
E=\left\{e_{1}, e_{2}, \ldots, e_{m}\right\}
$$

where $E$ is the set of radar target echoes and $e_{n}$ stands for the $n$th radar target echo.

\section{Near-Field Route Optimization Problem for Ship Navigation in Polar Ice-Covered Waters}

Ship officials are supposed to consistently change the ship heading angle to avoid potential thick sea ice in polar channels for the purpose of maritime traffic safety. It is noted that ice floes may randomly drift under the influence of wind. Therefore, ship crew must minimize the navigational risk by avoiding potential areas of sea ice with the minimum travel distance (i.e., low cost and short time). It is found that the objectives of the minimum sailing distance and a smaller risk level cannot be easily achieved (i.e., a shorter distance may be associated with a more dangerous ship route in the real world). Specifically, a ship may detour its routes in ice 

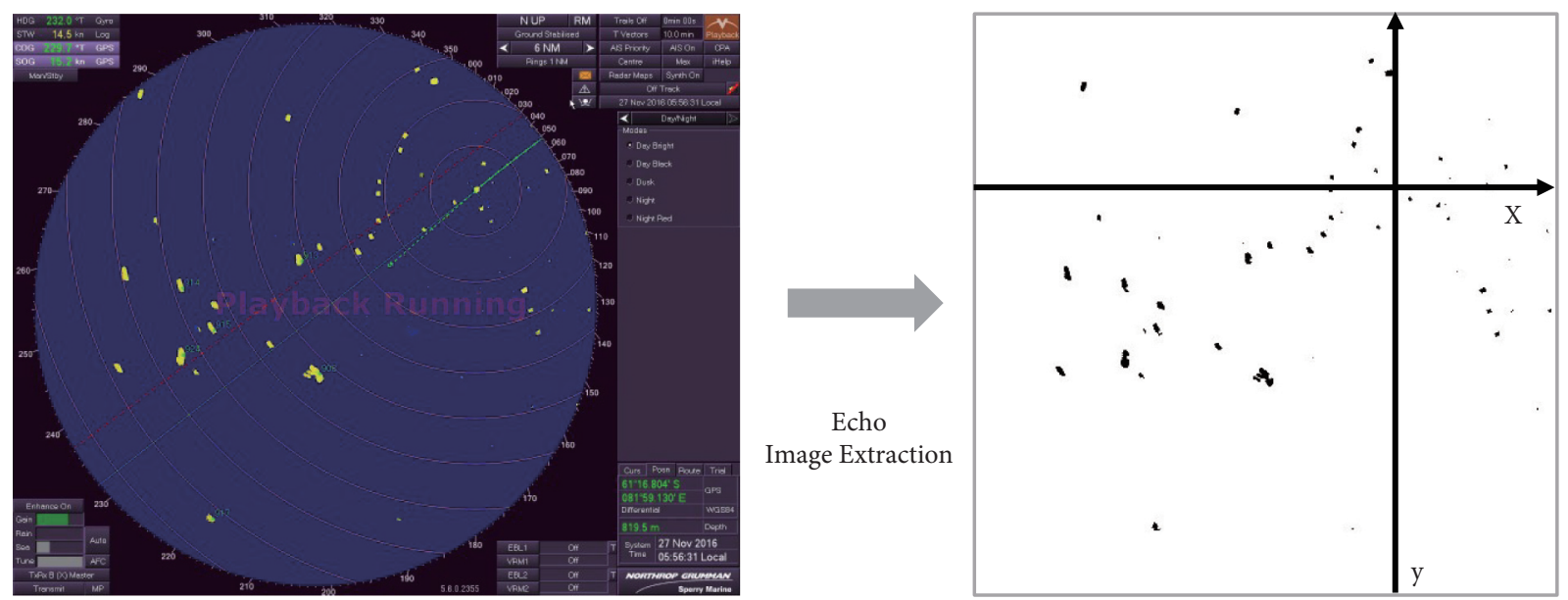

(a)

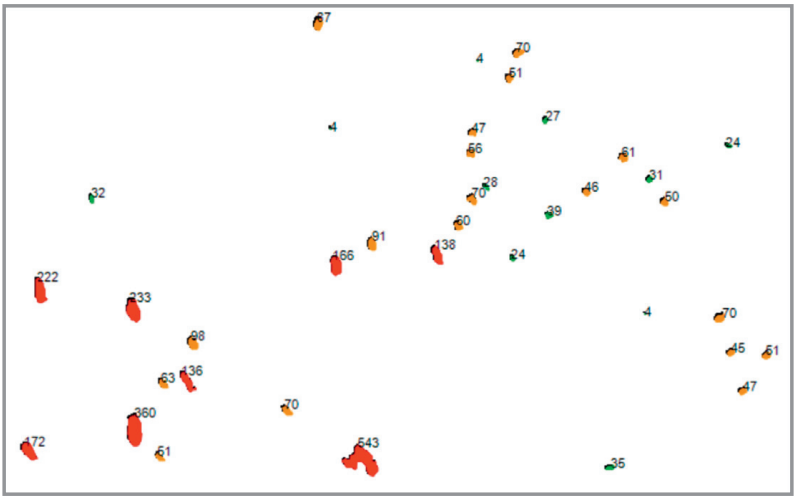

(b)

Figure 3: Preprocessing and recognition of ice radar images. (a) Segment the background and targets. (b) Label the targets.

areas to steer clear of navigational obstacles (e.g., sea ice and submerged reefs). Hence, a ship's travel distance and estimated time of arrival (ETA) may exceed those anticipated, which can lead to significant additional cost.

Figure 4 shows a typical ship voyage in polar areas with complex ice navigation conditions. The ship sails among the floating ice in the channel and is required to pass turning point $p_{1}, p_{2}, \ldots, p_{n-1}$ from the current position $p_{0}$ to the target position $p_{n}$. The ship sailing distance is obtained as

$$
D_{t}=\sum_{i=0}^{n-1} L\left(p_{i}, p_{i+1}\right),
$$

where $L\left(p_{i}, p_{i+1}\right)$ represents the distance between turning points $p_{i}$ and $p_{i+1}$. The vectors of each leg-line of the route are $V_{1}, V_{2}, \ldots, V_{n}$. The equation of the straight line in the Cartesian coordinate system of each leg-line is

$$
w_{i} x_{i}+r_{i}=0, \quad i=1,2, \ldots, n,
$$

and the minimum distance from the radar target echo to the leg-line is

$$
d_{i}=\frac{\left|w_{i} x_{i}+r_{i}\right|}{\left\|w_{i}\right\|}-\hat{d}_{i},
$$

where $\hat{d}_{i}=\sqrt{S_{e} / \pi}$ is the distance between the radar scanning center and the target.

In that way, we can obtain the minimum distance from the route to the sea-ice echo:

$$
d_{\min }=\min \left\{d_{1}, d_{2}, \ldots, d_{n}\right\} .
$$

The overall risk of navigation is minimized by obtaining the maximum distance between the route and the sea ice:

$$
\max _{d} d_{\min }=\max _{d} \min \left\{d_{1}, d_{2}, \ldots, d_{n}\right\}
$$

and the navigation risk minimization problem can be expressed as

$$
\begin{aligned}
& \min _{p} f_{1}(p)=\min _{p} \frac{1}{d_{\text {min }}+\epsilon}, \\
& \text { subject to } p_{i} \in \mathbb{R}^{2}, \quad i=1,2, \ldots, n, \\
& -1 \leq \vartheta \leq a_{i}=\arccos \left(\frac{V_{i-1} \cdot V_{i}}{\left\|V_{i-1}\right\|\left\|V_{i}\right\|}\right) \leq 1, \\
& \epsilon>0 .
\end{aligned}
$$




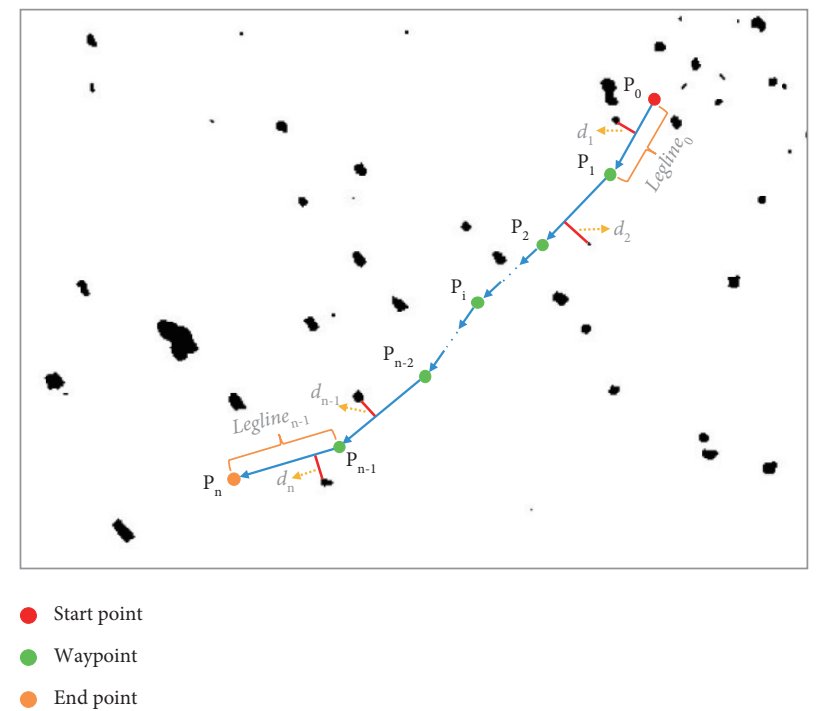

FIGURE 4: Ship path exploitation with complicated ice navigation conditions.

The problem of minimizing the navigation distance is further obtained as

$$
\begin{aligned}
& \min _{p} f_{2}(p)=\min _{p} \sum_{i=0}^{n-1} L\left(p_{i}, p_{i+1}\right), \\
& \text { subject to } p_{i} \in \mathbb{R}^{2} .
\end{aligned}
$$

\section{MOEAs for Near-Field Route Optimization Problem}

Ship routing in ice areas is a typical multiobjective optimization problem, which can be considered as a complex multiobjective, multivariable, and multidynamic constraint optimization problem. NSGA-II is a fast and effective method to solve a multiobjective optimization problem, which can maintain diversity and uniformity of Pareto solutions, improve the convergence speed and stability, and obtain more accurate optimal approximation solutions. To that aim, we propose a dynamic route optimization method based on NSGA-II to solve the polar region navigation optimization problem:

$$
\begin{aligned}
& \min _{p \in \Omega}=\left[f_{1}(p), f_{2}(p)\right], \\
& \text { subject to } \quad p \in \Omega,
\end{aligned}
$$

where $f=\left[f_{1}, f_{2}\right]$ is the objective vector defined in the objective space $\Theta \in \mathbb{R}^{2}$, the waypoint of the optimized route $p=\left[p_{1}, p_{2}, \ldots, p_{n}\right]$ is the decision vector, and $\Omega \in \mathbb{R}^{2}$ is the feasible decision space.

Note that objectives in the objective space are in disorder, and the solution of the multiobjective problem is obtained on the basis of the Pareto dominance relation. This is also used to define the concepts of optimality in multiobjective optimization. For given solutions $p$ and $q$ from $\Omega$, we consider that $q$ determines the $p$ (denoted by $p \prec q$ ) when

$$
\begin{aligned}
& \forall i \in\{1,2, \ldots, m\}: f_{i}(p) \leq f_{i}(q) \wedge \\
& \exists j \in\{1,2, \ldots, m\}: f_{j}(p)<f_{j}(q) .
\end{aligned}
$$

Individuals $p=\left[p_{1}, p_{2}, \ldots, p_{n}\right]$ are initially composed of $n$ waypoints with the support of Gray code. The fitness of each individual of $P_{0}$ is calculated by minimizing the objective cost function, the solutions are sorted based on fast nondomination sorting, and each solution is assigned a fitness weight based on the nondomination level. The binary tournament selection, recombination, and mutation operators are used to create a child population $Q_{0}$ of size $N$.

The main loop of the algorithm is shown as Algorithm 1. A combined population $R_{t}=P_{t} \cup Q_{t}$ is formed in the main loop, and a combined population $R_{t}$ is sorted according to nondomination. The new parent population $P_{t+1}$ is formed by adding solutions from the first step until the size is larger than $N$. The solutions of the last accepted front are sorted according to $\succcurlyeq_{n}$, and the first $N$ points are obtained. The population size $N$ is used for selection, crossover, and mutation to create a new population, $Q_{t+1}$. The algorithm continues until the population reaches the maximum number of generations. In this manner, we can choose appropriate yet user-preferred individuals, trading off between maritime safety and ship traveling distance, which are decoded to the waypoints of the optimal route.

\section{Ice Route Optimization Framework}

We propose a macroscale route plan framework based on sea-ice concentration data with the support of an $A^{*}$-based route optimization model, so as to apply a near-field ice navigation approach in polar ice areas (see Figure 5). Macroscale route optimization is based on the fusion data of sea-ice density data and thickness data. It provides a global route design method for near-field route optimization to prevent it from falling into local optimization. 


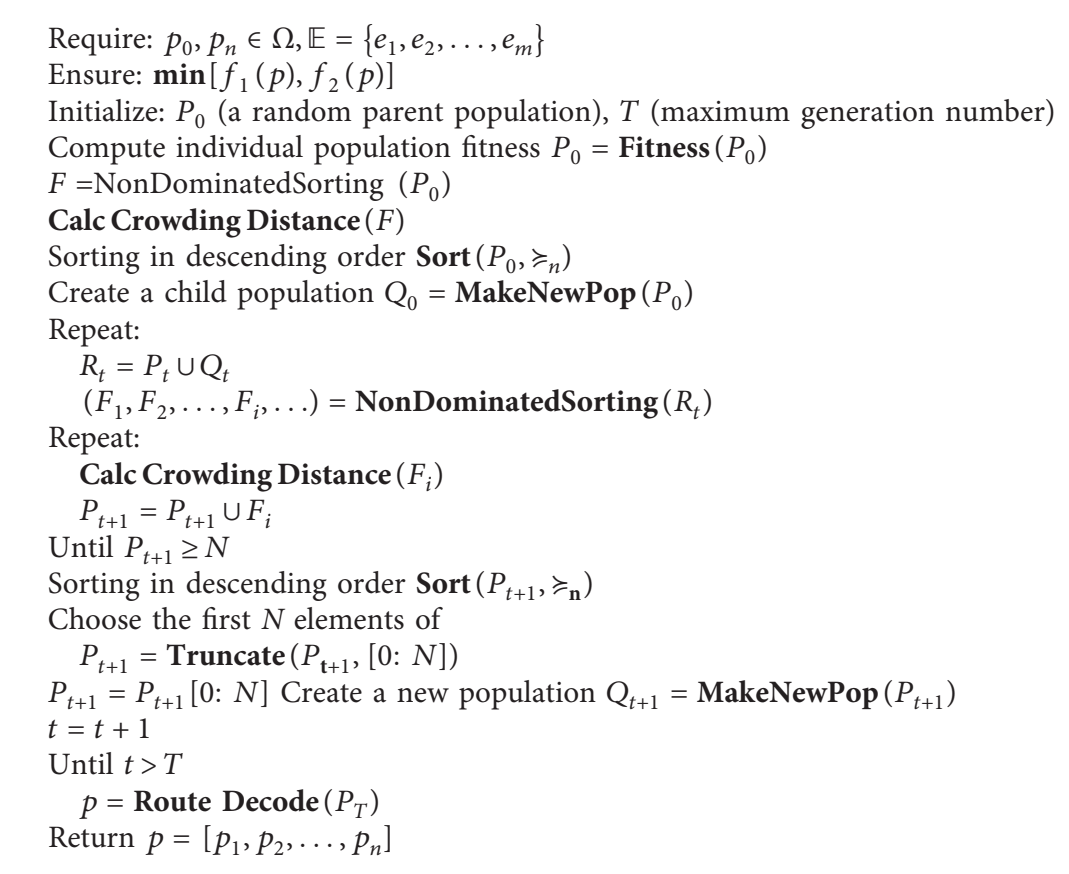

Algorithm 1: NSGA-II-based near-field route optimization algorithm.

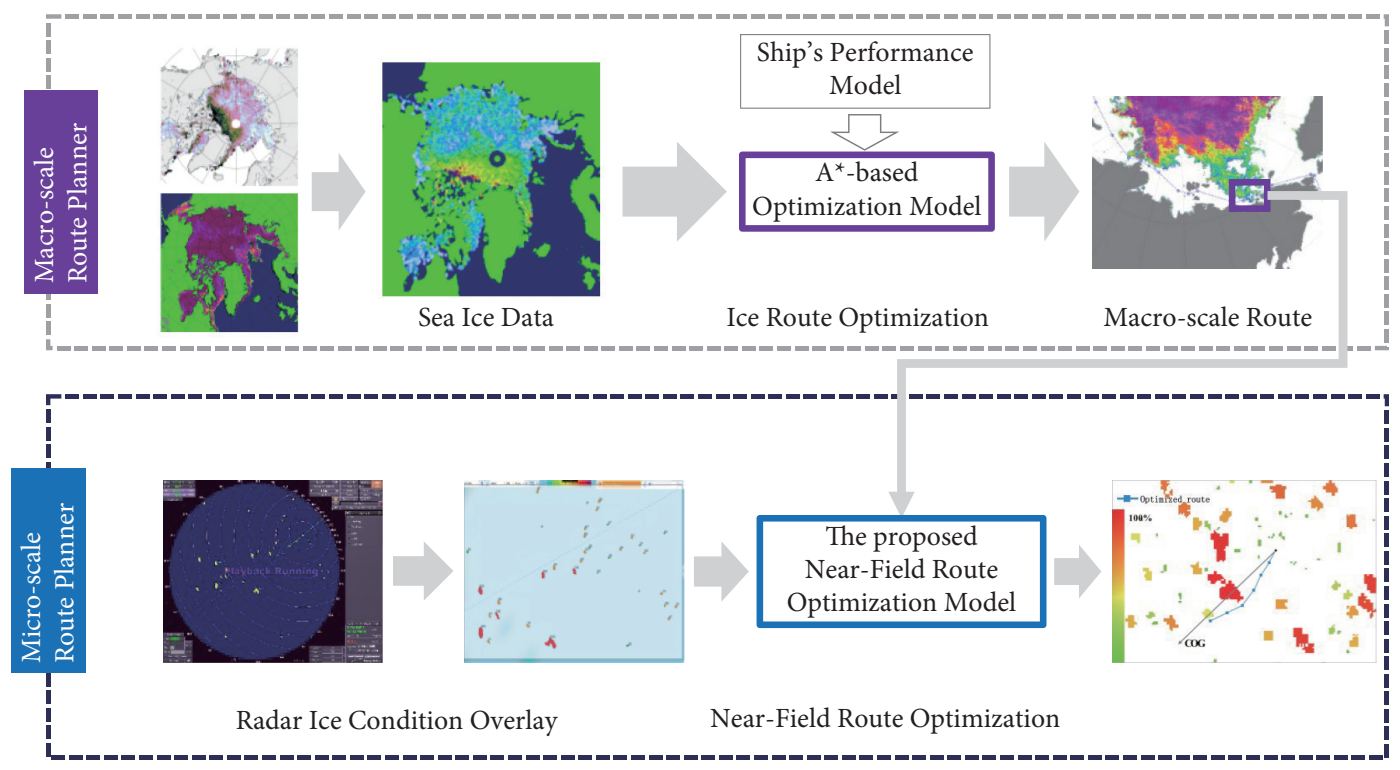

FIGURE 5: Framework overview for ship route optimization in polar ice area.

Macroscale route optimization aims to avoid the dense seaice area and provide an initial path for near-field route optimization.

5.1. Sea-Ice Map-Based Macroscale Route Plan. The sea-ice concentration data and electronic navigational chart (ENC) data are used to build the $A^{*}$ grid, and each node is filled with a value indicating its availability (see Figure 6). The cost function,

$$
f(n)=g(n)+h(n),
$$

is used to evaluate the priority of the eight neighbours of the node in the $A^{*}$ algorithm, where $n$ is the following node on the path and $g(n)$ is the path cost from the starting node to $n$. The heuristic function $h(n)$ estimates the shortest path cost linking nodes $n$ to the end. The parameter $f(n)$ represents the overall cost from the beginning node to the end. The task is to minimize $f(n)$ by traversing the grid nodes. 


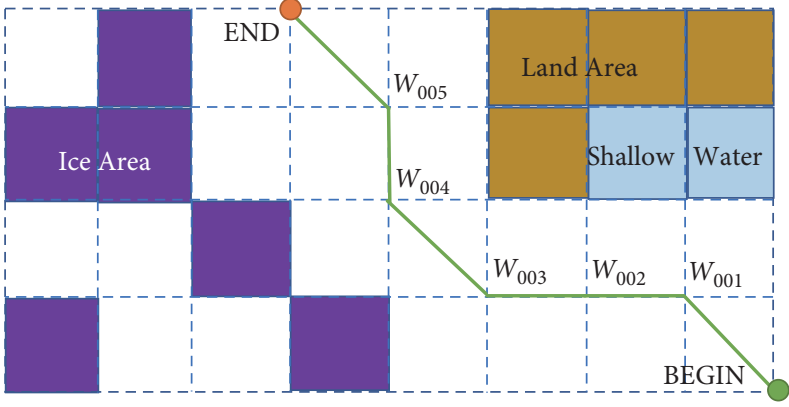

(a)

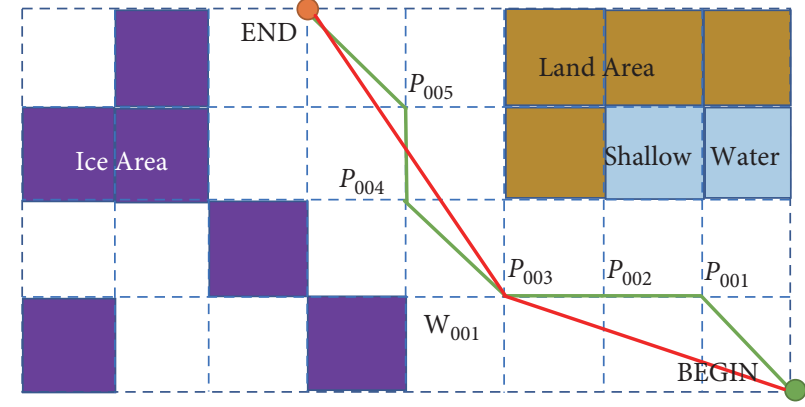

(b)

FIgURE 6: Path search space for $A^{*}$ algorithm. (a) Initial path obtained by $A^{*}$ algorithm. (b) Optimized ship path.

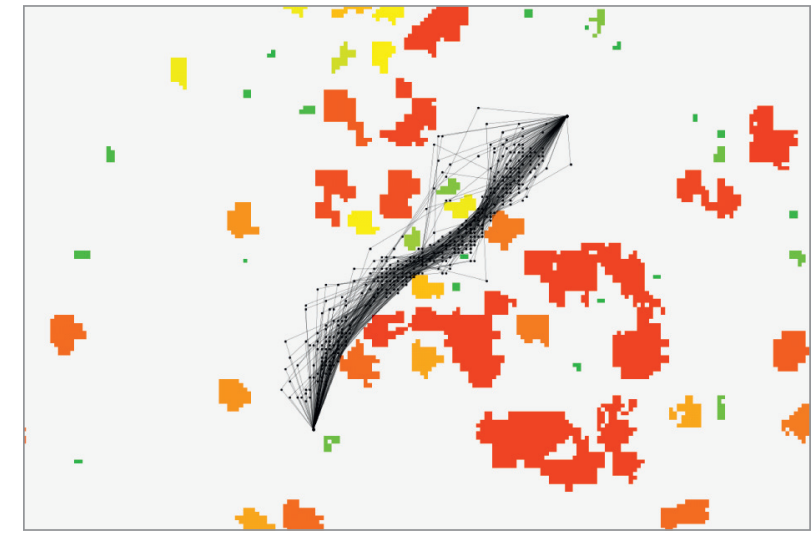

FIGURE 7: Ship route optimization by proposed near-field route optimization model.

A series of adjacent grid nodes, $\left\{W_{001}, W_{002}, \ldots\right\}$, can be obtained through the $A^{*}$ algorithm with the above grid data, and a route is formed by connecting the nodes. But such a path, if obtained from a discretized grid, may not accurately describe the operational path, so a relaxation smoothing algorithm is employed to generate the operational route by suppressing the redundant nodes (see Figure 6(b)).

5.2. Radar Echo-Based Microscale Route Planner. Sea-ice concentration data are automatically downloaded from the NOAA website and superposed on the electrical nautical chart. Real-time radar echo scanning video is collected from the ship radar system, and the radar echoes are preprocessed with the proposed ice condition recognition model. The radar echoes are overlaid on the electrical nautical charts. Note that the own-ship position is regarded as the initial ship position, and the following waypoint is obtained by a macroscale route designing model based on sea-ice concentration data. The proposed near-field route optimization approach is employed to iteratively optimize the routes (the model is run 200 times), as shown in Figure 7. It is found that the optimized routes can be very similar, and the cluster method is further used to extract a central path, as shown in Figure 8. The ship will follow the updated yet optimized course (as the recommended course) when the course deviation between the new and original courses exceeds the threshold $\theta$. The radar echo images will then be updated and processed in real time, and the ship's route will be recursively updated, as shown in Figure 9.

\section{Experiments}

6.1. Experimental Database. We use the ice density data of the University of Bremen and the thickness data of NSIDC, because of their high coverage of sea-ice data in the poles. We collected raw radar data for near-field route optimization from a research-based icebreaker ship, named Xuelong, and obtained its navigation data during a voyage to Zhongshan Station in the Antarctic ice area in November 2016. The sea-ice concentration and radar video data were also collected. We present typical images for sea-ice concentration data and radar echoes in Figure 10.

6.2. Experimental Setup. For the purpose of model performance evaluation, we used the proposed macroscale route planner to design an initial route based on the sea-ice concentration data with the $A^{*}$ algorithm, and a qualitative analysis was implemented to check the ice-avoidance efficiency via the prespecified sea-ice concentration data. The radar video data were continuously replayed, and thus the proposed near-field route optimization route was against the ship trajectory in the real world in each radar image for the purpose of model effectiveness verification. Note that the target ship may not sail exactly on the recommended course. 


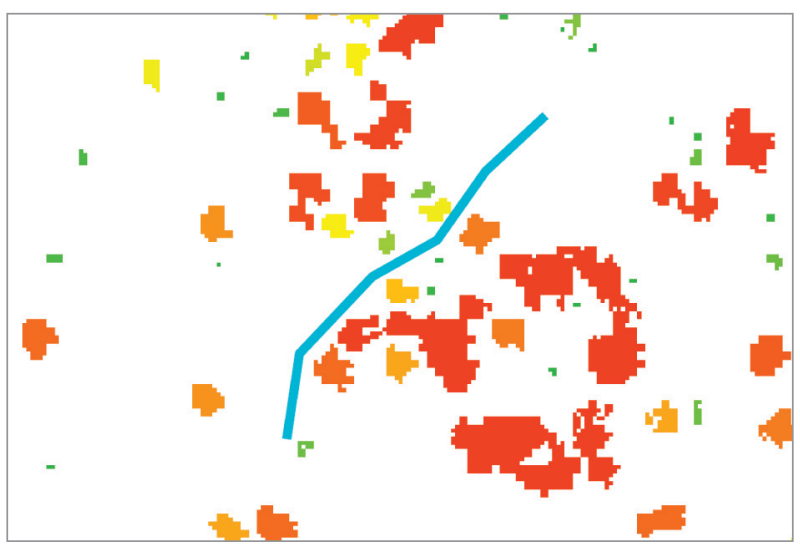

FiguRE 8: Trajectory map of cluster center for optimized routes.

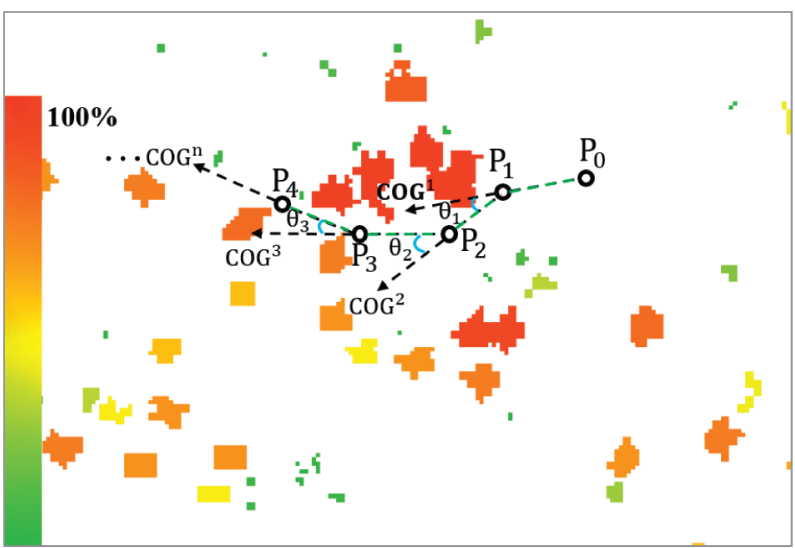

Figure 9: Optimization procedure for near-field route optimization model.
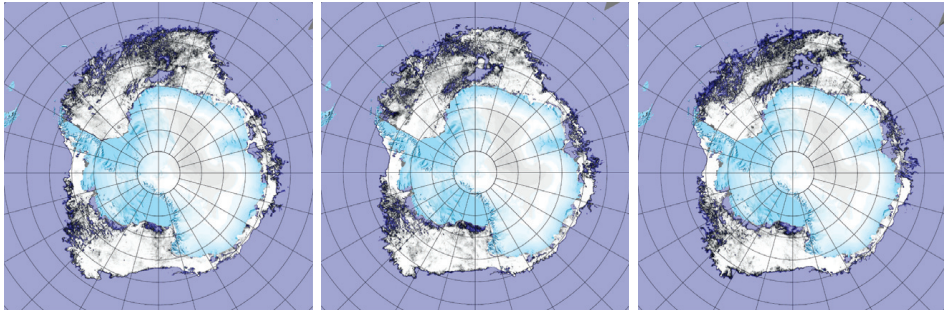

(a)
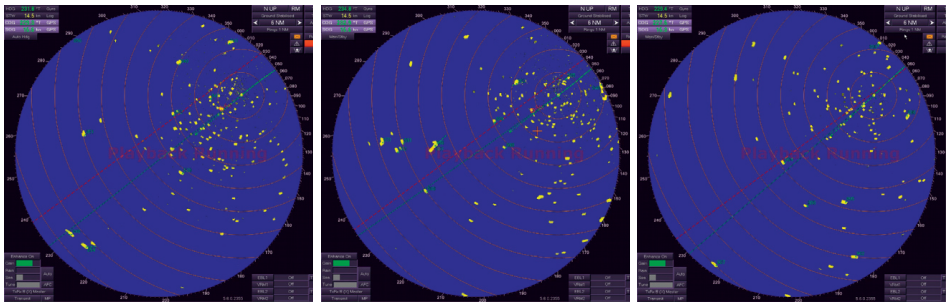
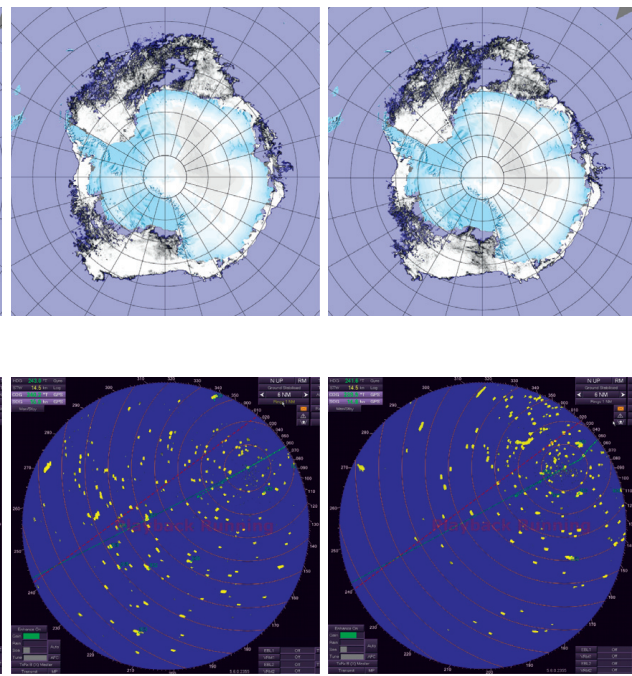

(b)

Figure 10: Typical images for sea-ice concentration data and radar echoes. (a) Sea-ice concentration data. (b) Radar echo images.

To address this issue, we analyzed the ship trajectory with a small-time interval while considering that the ship sails on its recommended course. We evaluated the ship displacement according to the playback voyage data with a time interval of several minutes. We selected three typical sea-ice navigation scenes for the purpose of verifying model performance, which are referred to as simple, normal, and complex (see Figure 11). 

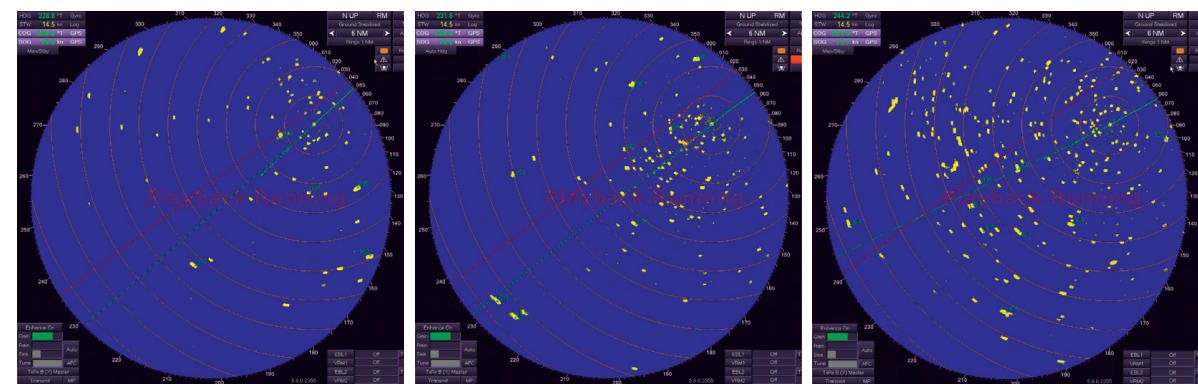

Figure 11: Radar echoes for three typical sea-ice navigation scenes.

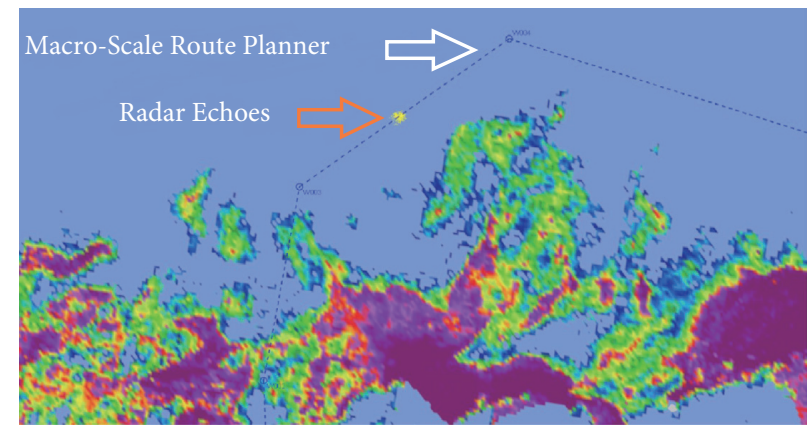

FIGURE 12: Overview of macroscale route planner.

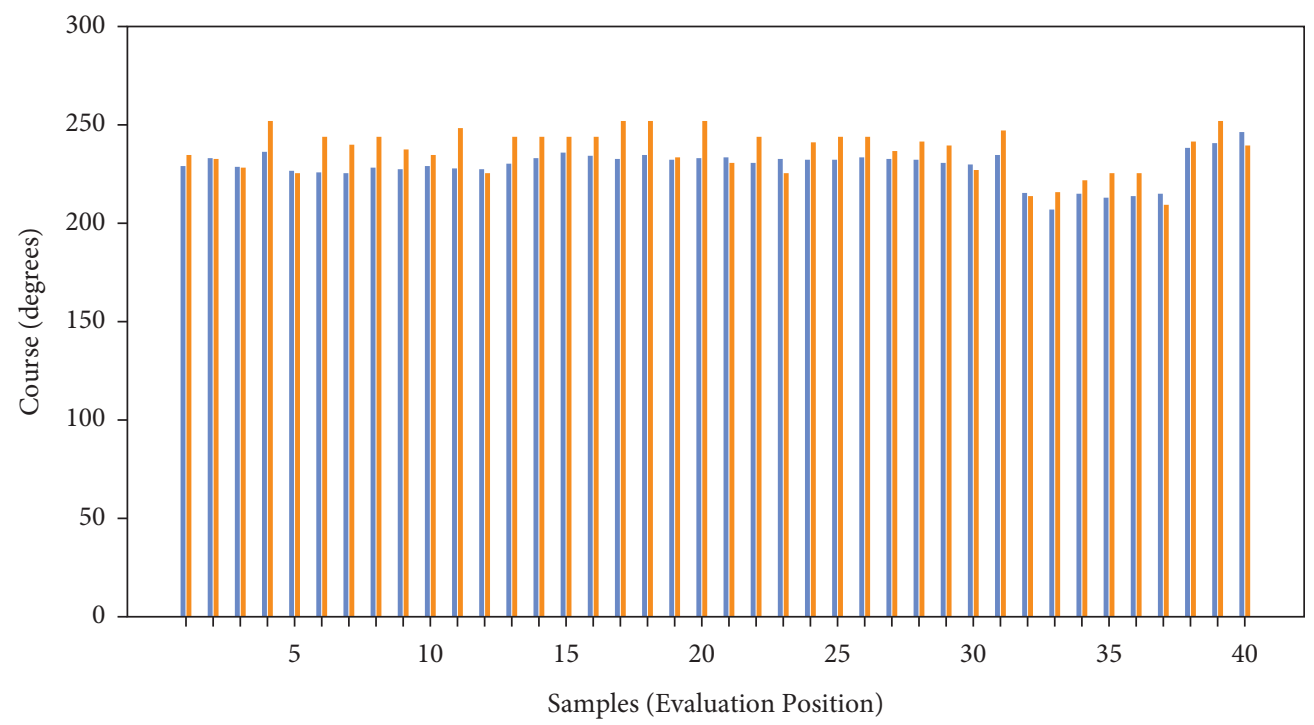

Actual course

Optimized course

(a)

FIgURE 13: Continued. 


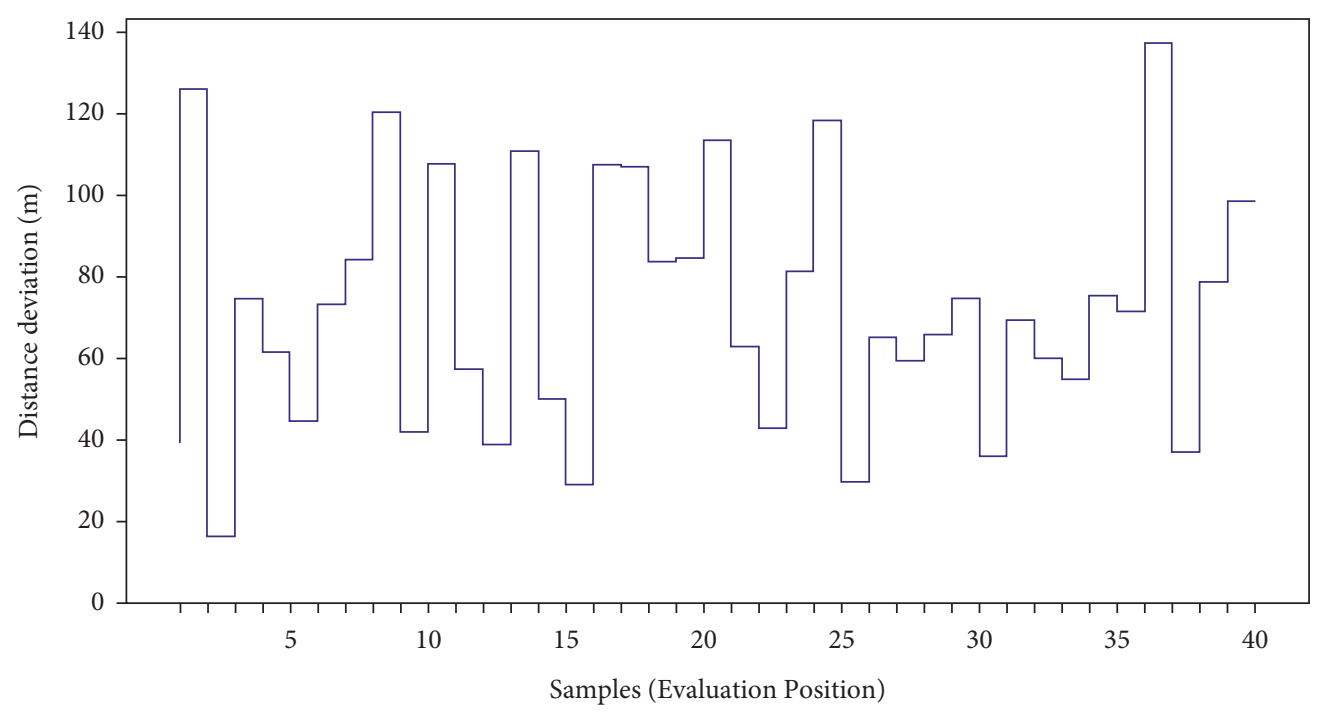

(b)

Figure 13: Performance of proposed model for simple sea-ice scene. (a) Recommended and actual courses for simple sea-ice scene. (b) Distance error distribution for simple sea-ice scene.

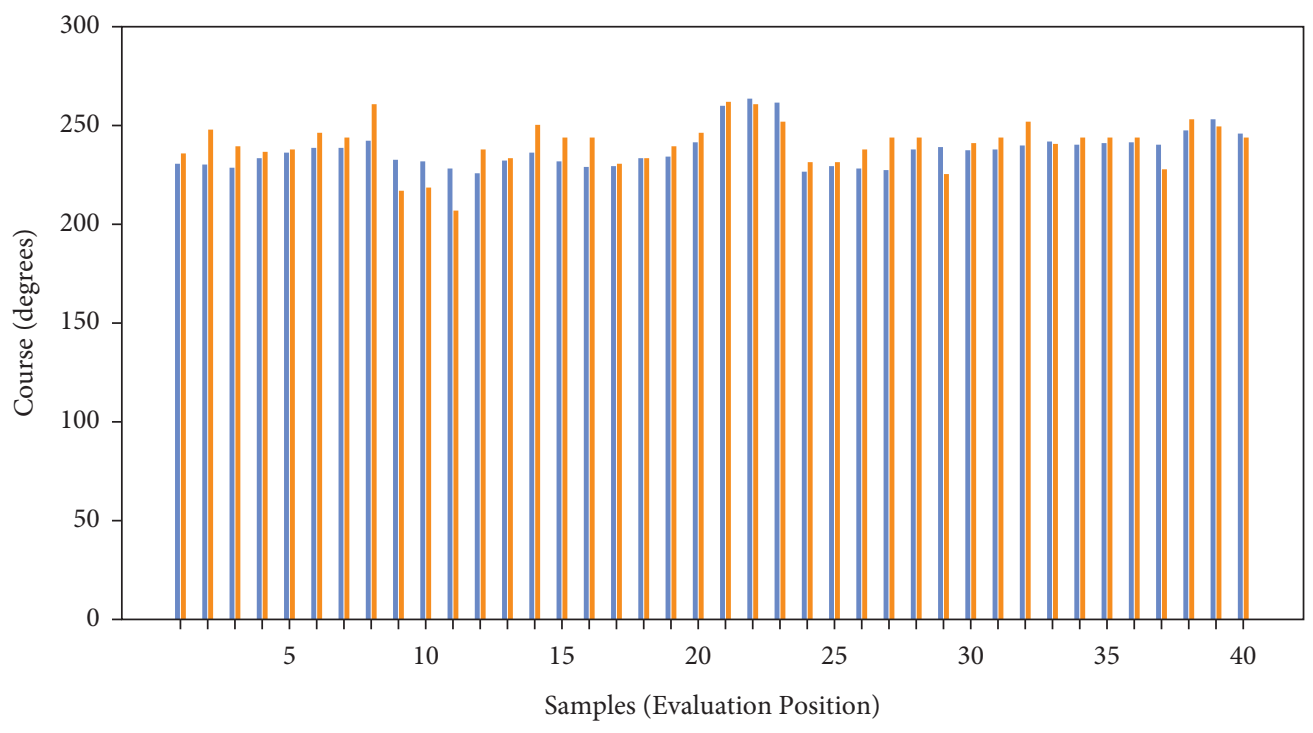

Actual course Optimized course

(a)

Figure 14: Continued. 


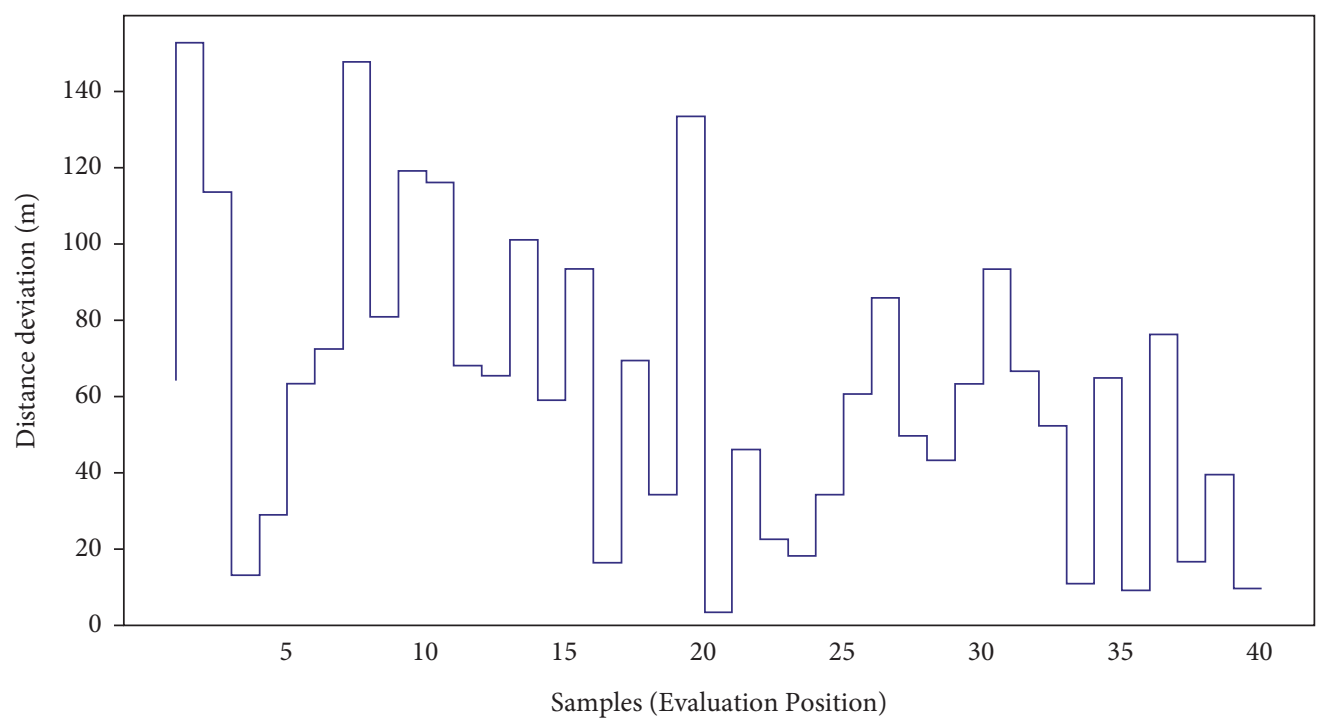

(b)

Figure 14: Performance of proposed model for normal sea-ice scene. (a) Recommended and actual courses for normal sea-ice scene. (b) Distance error distribution for simple sea-ice scene.

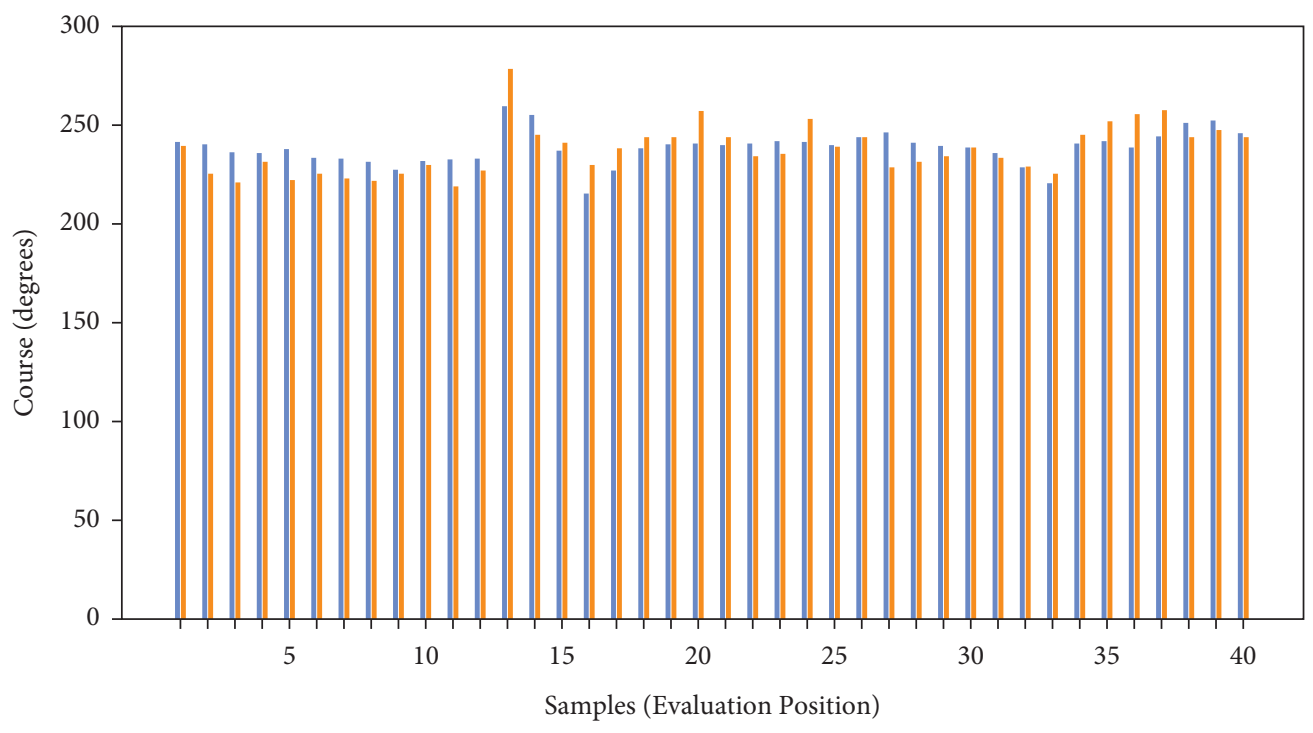

Actual course

Optimized course

(a)

Figure 15: Continued. 


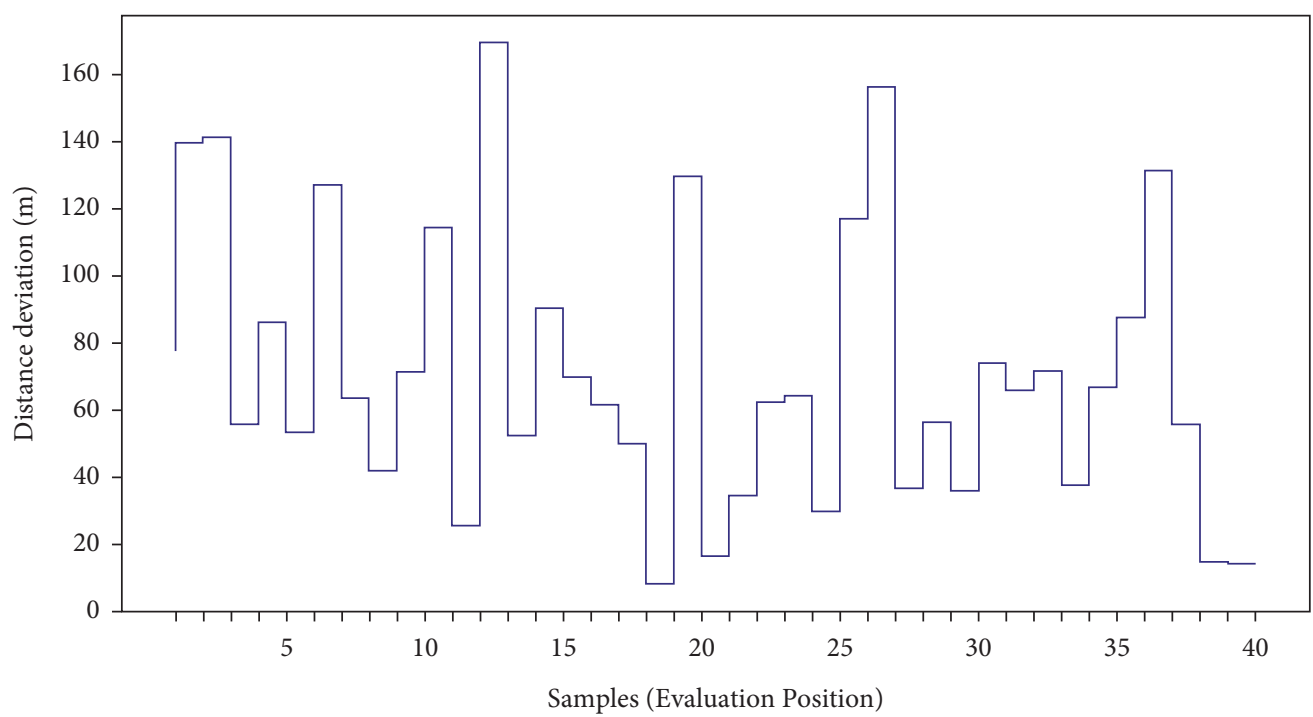

(b)

Figure 15: Performance of proposed model for complex sea-ice scene. (a) Recommended and actual courses for complex sea-ice scene. (b) Distance error distribution for complex sea-ice scene.

TABle 1: Course and distance error distributions for optimized route.

\begin{tabular}{lcccccc}
\hline $\begin{array}{l}\text { Optimized } \\
\text { scenes }\end{array}$ & $\begin{array}{c}\text { Average distance } \\
\text { deviation }(\mathrm{m})\end{array}$ & $\begin{array}{c}\text { Variance of } \\
\text { distance deviation } \\
(\mathrm{m})\end{array}$ & $\begin{array}{c}\text { Max distance } \\
\text { deviation }(\mathrm{m})\end{array}$ & $\begin{array}{c}\text { Average course } \\
\text { deviation } \\
\text { (degrees) }\end{array}$ & $\begin{array}{c}\text { Variance of course } \\
\text { deviation (degrees) }\end{array}$ & $\begin{array}{c}\text { Max course deviation } \\
(\text { degrees })\end{array}$ \\
\hline Simple & 72.45 & 30.04 & 137.31 & 9.17 & 5.64 & 20.50 \\
Normal & 61.66 & 39.48 & 153.17 & 7.62 & 5.78 & 21.33 \\
Complex & 71.68 & 41.22 & 169.63 & 7.87 & 5.48 & 18.93 \\
Average & 68.59 & 37.25 & 169.63 & 8.22 & 5.63 & 21.33 \\
\hline
\end{tabular}

6.3. Experimental Results. The sea-ice concentration data were overlaid on the ENC layer, and an optimized route was found by using a macroscale route planner based on the $A^{*}$ route optimization model (see Figure 12). For the purpose of model performance comparison, real-time radar echoes were loaded into the route optimization system, which was overlaid on the ENC layer.

Figure 13(a) shows recommended and actual courses at different evaluation positions under a simple continuous scene. Note that the average course deviation is 9.17 degrees. Figure 13(b) shows distance deviations at different evaluation positions, whose average is 72.45 meters per 4 minutes. Figures 14(a) and 15(a) present the comparison results between the recommended and actual courses at different positions for normal and complex continuous traffic scenarios, respectively. The average course deviations for the normal and complex scenes are 7.62 degrees and 7.87 degrees, respectively.

Figures 14(b) and 15(b) show the distance deviation in different evaluation positions in the normal and complex continuous scenes, respectively. In the normal and complex scenes, the average distance deviations are 61.66 meters and 71.68 meters, respectively, per 4 minutes. The experimental results suggest that recommended optimized courses are always close to the actual course, with small course errors.

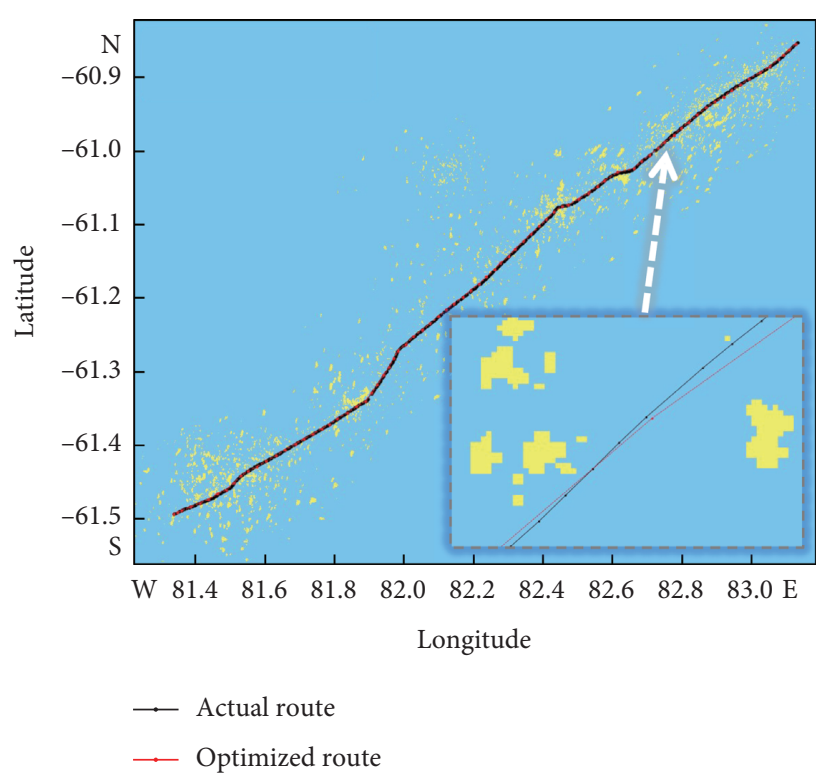

FIgURE 16: Recommended and actual ship sailing trajectories.

Table 1 summarizes distributions for the average distance deviation, average course deviation, max distance deviation, and max course deviation. Note that the overall 


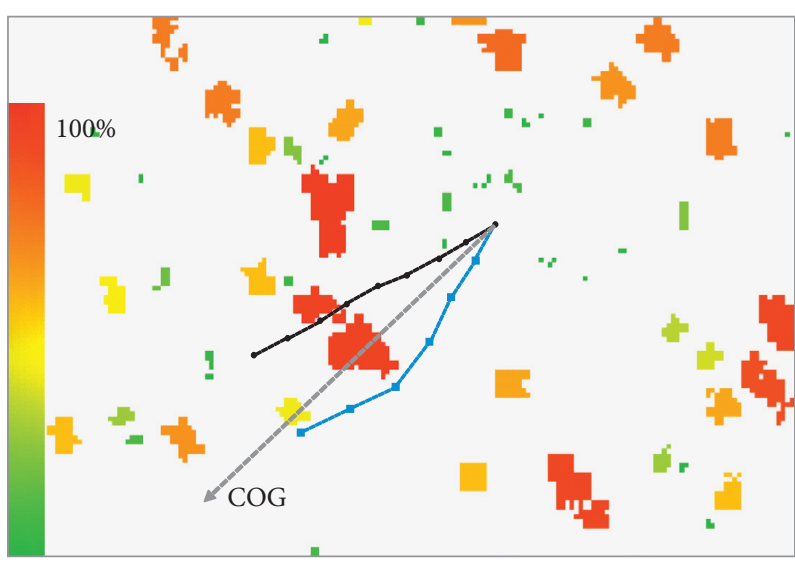

- Actual route

- - Optimized route

(a)

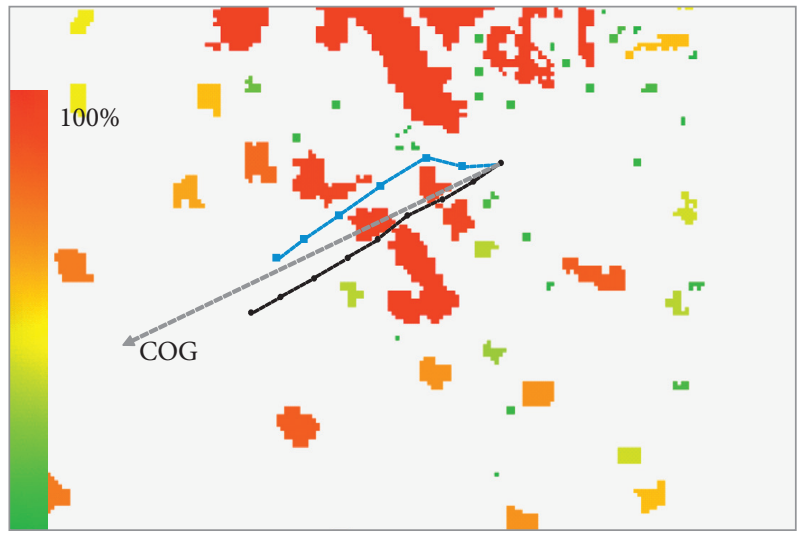

- Actual route

- Optimized route

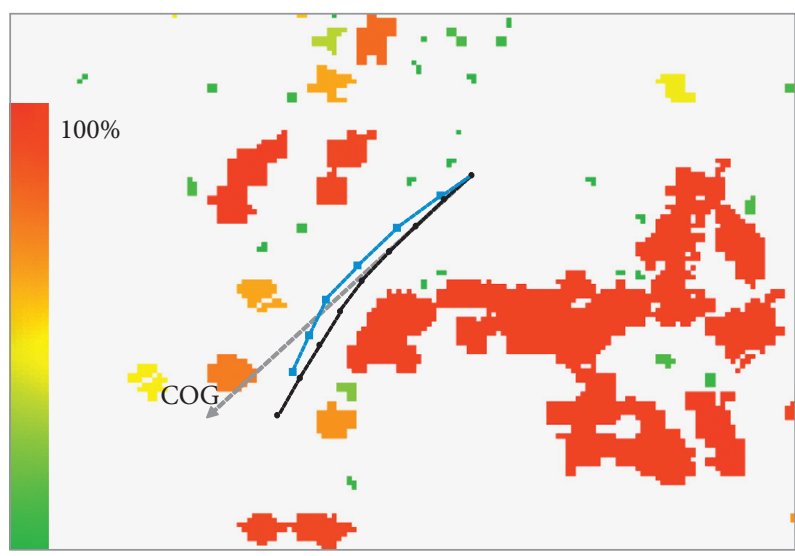

- - Actual route

- - Optimized route

(b)

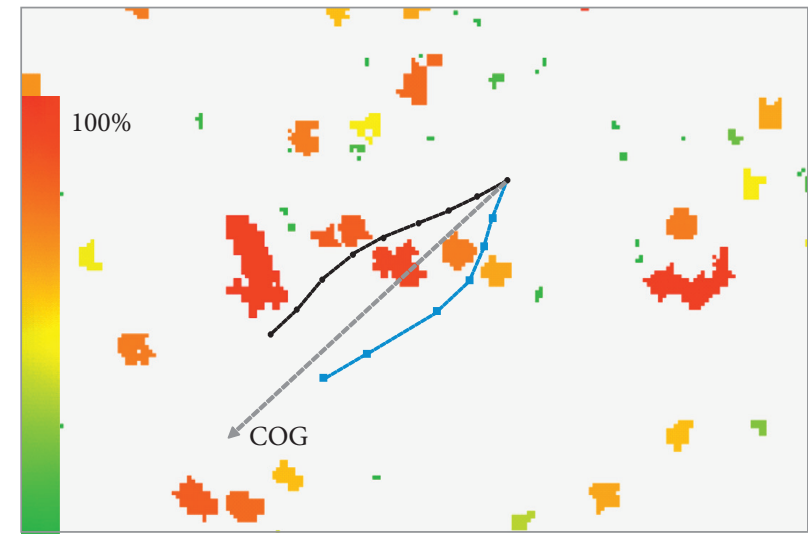

- - Actual route

- - Optimized route

(c)

(d)

FIGURE 17: Difference between predicted and actual routes in some situations.

average course deviation is 8.22 degrees, while the total average distance deviation is $68.59 \mathrm{~m}$. Table 1 indicates that an adverse navigation environment (i.e., complicated sea-ice condition) did not obviously degrade the model performance. Figure 16 presents the actual and model-recommended trajectories, which are quite close. Figure 17 shows that the model-predicted trajectory may differ slightly from that in the real world in certain traffic situations, mainly because our model suggested a more reasonable ship travel route, with a higher maritime traffic safety level and smaller travel distance.

\section{Conclusion}

We presented a framework to identify optimal ship routes in polar areas based on sea-ice concentration and radar images. A macroscale route planner obtains a potential ship trajectory based on sea-ice concentration data. The nearfield route planner can dynamically and accurately update routes according to sea-ice situations. A proposed near- field route planner further determines the optimal ship trajectory based on radar echo images. Experimental results suggested that our proposed framework can provide accurate yet reasonable ship routes in ice areas. In the future, we can enhance our model's performance by integrating additional evolution algorithms (e.g., a genetic algorithm), and shipborne ice breaker influence on the proposed model's performance under typical maritime traffic scenarios can be verified.

\section{Data Availability}

The data presented in this study are available from the corresponding author upon request.

\section{Conflicts of Interest}

The authors declare that they have no conflicts of interest regarding the publication of this study. 


\section{Acknowledgments}

This work was supported in part by the National Key Research and Development Project of China (Grant no. 2019YFB1600605), National Natural Science Foundation of China (Grants nos. 51709167 and 61701299), Shanghai Science and Technology Innovation Action Plan (Grant no. 18DZ1206101), Shanghai Pujiang Project (Grant no. 18PJD017), and Shanghai National Natural Science Foundation (Grant no. 18ZR1417100).

\section{References}

[1] S. R. Stephenson, W. Wang, C. S. Zender, H. Wang, S. J. Davis, and P. J. Rasch, "Climatic responses to future trans-arctic shipping," Geophysical Research Letters, vol. 45, no. 18, pp. 9898-9908, 2018.

[2] F. Lasserre and S. Pelletier, "Polar super seaways? Maritime transport in the Arctic: an analysis of shipowners' intentions," Journal of Transport Geography, vol. 19, no. 6, pp. 1465-1473, 2011.

[3] S. Kum and B. Sahin, "A survey on ice navigation research," Transactions of Navigation, vol. 1, no. 1, pp. 23-28, 2016.

[4] Y. Aksenov, E. E. Popova, A. Yool et al., "On the future navigability of Arctic sea routes: high-resolution projections of the Arctic Ocean and sea ice," Marine Policy, vol. 75, pp. 300-317, 2016.

[5] L. Beveridge, M. Fournier, F. Lasserre, L. Huang, and P.-L. Têtu, "Interest of Asian shipping companies in navigating the Arctic," Polar Science, vol. 10, no. 3, pp. 404-414, 2016.

[6] S. Kum and B. Sahin, "A root cause analysis for Arctic Marine accidents from 1993 to 2011," Safety Science, vol. 74, pp. 206-220, 2015.

[7] S. Fu, D. Zhang, J. Montewka, X. Yan, and E. Zio, “Towards a probabilistic model for predicting ship besetting in ice in Arctic waters," Reliability Engineering \& System Safety, vol. 155, pp. 124-136, 2016.

[8] R. J. Bye and A. L. Aalberg, "Maritime navigation accidents and risk indicators: an exploratory statistical analysis using AIS data and accident reports," Reliability Engineering \& System Safety, vol. 176, pp. 174-186, 2018.

[9] F. Goerlandt, H. Goite, O. A. Valdez Banda, A. Höglund, P. Ahonen-Rainio, and M. Lensu, "An analysis of wintertime navigational accidents in the Northern Baltic Sea," Safety Science, vol. 92, pp. 66-84, 2017.

[10] F. Goerlandt, J. Montewka, W. Zhang, and P. Kujala, “An analysis of ship escort and convoy operations in ice conditions," Safety Science, vol. 95, pp. 198-209, 2017.

[11] S. Ghosh and C. Rubly, "The emergence of Arctic shipping: issues, threats, costs, and risk-mitigating strategies of the polar code," Australian Journal of Maritime \& Ocean Affairs, vol. 7, no. 3, pp. 171-182, 2015.

[12] X. Chen, S. Wang, C. Shi, H. Wu, J. Zhao, and J. Fu, "Robust ship tracking via multi-view learning and sparse representation," Journal of Navigation, vol. 72, no. 1, pp. 176-192, 2019.

[13] N. S. Lewis, L. Koenig, G. Grant et al., "Sea ice detection from persistent single-channel shortwave infrared satellite data," Ecological Informatics, vol. 52, pp. 139-149, 2019.

[14] X. Chen, L. Qi, Y. Yang et al., "Video-based detection infrastructure enhancement for automated ship recognition and behavior analysis," Journal of Advanced Transportation, vol. 2020, Article ID 7194342, 12 pages, 2020.
[15] V. Lehtola, J. Montewka, F. Goerlandt, R. Guinness, and M. Lensu, "Finding safe and effcient shipping routes in icecovered waters: a framework and a model," Cold Regions Science and Technology, vol. 165, pp. 1-14, Article ID 102795, 2019.

[16] V. Kotovirta, R. Jalonen, L. Axell, K. Riska, and R. Berglund, "A system for route optimization in ice-covered waters," Cold Regions Science and Technology, vol. 55, no. 1, pp. 52-62, 2009.

[17] G. Robert, J. Saarimaki, L. Ruotsalainen et al., "A method for ice-aware maritime route optimization," in Proceedings of the 2014 IEEE/ION Position, Location and Navigation Symposium-Plans, pp. 1371-1378, Monterey, CA, USA, May 2014.

[18] J.-H. Nam, I. Park, H. J. Lee, M. O. Kwon, K. Choi, and Y.-K. Seo, "Simulation of optimal arctic routes using a numerical sea ice model based on an ice-coupled ocean circulation method," International Journal of Naval Architecture and Ocean Engineering, vol. 5, no. 2, pp. 210-226, 2013.

[19] S. Patrick, "Dynamic routing through waters partially covered with sea ice," in Proceedings of the OTC Arctic Technology Conference \& Offshore Technology Conference, Houston, TX, USA, February 2014.

[20] M. Zhang, D. Zhang, S. Fu, and C. Zhang, "A method for planning arctic sea routes under multi-constraint conditions," in Proceedings of the 24th International Conference On Port and Ocean Engineering under Arctic Conditions, Busan, Korea, 2018.

[21] P. Zvyagin and A. Voitkunskaia, "Model of transit transport in arctic based on graph algorithms," in Proceedings of the International Conference on Offshore Mechanics and Arctic Engineering, vol. 49996, Busan, Korea, June 2016.

[22] M. Choi, H. Chung, H. Yamaguchi, and K. Nagakawa, "Arctic sea route path planning based on an uncertain ice prediction model," Cold Regions Science and Technology, vol. 109, pp. 61-69, 2015.

[23] F. Hui, T. Zhao, X. Li et al., "Satellite-based sea ice navigation for prydz bay, east Antarctica," Remote Sensing, vol. 9, no. 6, Article ID 518, 2017.

[24] X. Liu, S. Sattar, and S. Li, "Towards an automatic ice navigation support system in the arctic sea," ISPRS International Journal of Geo-Information, vol. 5, no. 3, Article ID 36, 2016.

[25] J. Montewka, F. Goerlandt, P. Kujala, and M. Lensu, “Towards probabilistic models for the prediction of a ship performance in dynamic ice," Cold Regions Science and Technology, vol. 112, pp. 14-28, 2015.

[26] L. Kuuliala, P. Kujala, M. Suominen, and J. Montewka, "Estimating operability of ships in ridged ice fields," Cold Regions Science and Technology, vol. 135, pp. 51-61, 2017.

[27] V. V. Lehtola, J. Montewka, and J. Salokannel, "Sea captains' views on automated ship route optimization in ice-covered waters," Journal of Navigation, vol. 73, no. 2, pp. 364-383, 2019.

[28] A. G. Topaj, O. V. Tarovik, A. A. Bakharev, and A. A. Kondratenko, "Optimal ice routing of a ship with icebreaker assistance," Applied Ocean Research, vol. 86, pp. 177-187, 2019.

[29] F. Li, F. Goerlandt, P. Kujala, J. Lehtiranta, and M. Lensu, "Evaluation of selected state-of-the-art methods for ship transit simulation in various ice conditions based on full-scale measurement," Cold Regions Science and Technology, vol. 151, pp. 94-108, 2018.

[30] M. Choi, H. Chung, H. Yamaguchi, and L. Waruna Arampath De Silva, "Application of genetic algorithm to ship route optimization in ice navigation," in Proceedings of the 
International Conference on Port and Ocean Engineering under Arctic Conditions, Trondheim, Norway, 2013.

[31] H. Piehl, A. S. A. Milakovic, and S. R. Ehlers, "A finite element method-based potential theory approach for optimal ice routing," Journal of Offshore Mechanics \& Arctic Engineering, vol. 139, no. 6, Article ID 061502, 2017.

[32] X. Chen, H. Chen, Y. Yang et al., "Traffic flow prediction by an ensemble framework with data denoising and deep learning model," Physica A: Statistical Mechanics and Its Applications, vol. 565, Article ID 125574, 2021.

[33] B. Wu, Y. Tang, X. Yan, and C. Guedes Soares, "Bayesian network modelling for safety management of electric vehicles transported in RoPax ships," Reliability Engineering \& System Safety, vol. 209, Article ID 107466, 2021.

[34] X. Chen, Z. Li, Y. Yang, L. Qi, and R. Ke, "High-resolution vehicle trajectory extraction and denoising from aerial videos," IEEE Transactions on Intelligent Transportation Systems, vol. 22, no. 5, pp. 3190-3202, 2021.

[35] B. Wu, J. Zhang, T. L. Yip, and C. Guedes Soares, "A quantitative decision-making model for emergency response to oil spill from ships," Maritime Policy \& Management, vol. 48, no. 3, pp. 299-315, 2020.

[36] R. Liu, W. Yuan, X. Chen, and Y. Lu, "An enhanced CNNenabled learning method for promoting ship detection in maritime surveillance system," Ocean Engineering, vol. 235, Article ID 109435, 2021.

[37] A. Zhou, B.-Y. Qu, H. Li, S.-Z. Zhao, P. N. Suganthan, and Q. Zhang, "Multiobjective evolutionary algorithms: a survey of the state of the art," Swarm and Evolutionary Computation, vol. 1, no. 1, pp. 32-49, 2011.

[38] X. Li, H. Wang, and Q. Wu, "Multi-objective optimization in ship weather routing," in Proceedings of the IEEE 2017 Constructive Nonsmooth Analysis and Related Topics, pp. 1-4, Saint Petersburg, Russia, May 2017.

[39] E. Zitzler, M. Laumanns, and L. Thiele, "SPEA2: Improving the strength pareto evolutionary algorithm for multiobjective optimization," in Proceedings of the Evolutionary Mehods for Design, Optimization and Control with Applications to Industrial Problems EUROGEN'2001, vol. 103, Athens. Greece, September 2001.

[40] K. Deb, A. Pratap, S. Agarwal, and T. Meyarivan, "A fast and elitist multiobjective genetic algorithm: NSGA-II," IEEE Transactions on Evolutionary Computation, vol. 6, no. 2, pp. 182-197, 2002.

[41] J. D. Knowles and D. W. Corne, "Approximating the nondominated front using the Pareto archived evolution strategy," Evolutionary Computation, vol. 8, no. 2, pp. 149-172, 2014.

[42] D. W. Corne, J. D. Knowles, and M. J. Oates, "The Pareto envelope-based selection algorithm for multiobjective optimization," in Proceedings of the International Conference on Parallel Problem Solving from Nature, pp. 839-848, Paris, France, September 2000. 